\title{
THE IMPACT OF ICT USE ON FLL IN DIFFERENT PERSONALITY TYPES
}

\author{
Marija Stanković, \\ Milica Čolović
}

\author{
Singidunum University \\ 32 Danijelova Street, Beograd, Serbia
}

\begin{abstract}
:
This paper concerns the effects of ICT use on the process of foreign language learning, specifically English for different personality types of learners. Our aim is to test whether the use of ICT in English classes, or at home, during students' primary and secondary education, has had an impact on students' language proficiency and whether and to what extent that impact has been influenced by students being introverted or extroverted. This small-scale research was carried out at Singidunum University, Centre Niš, with the first year students whose knowledge of English ranges from A1 to B2. Based on the results obtained, it can be noticed that there is a significant correlation between the personality type and teaching methods in relation to language learning. Furthermore, in terms of frequency and purposes of ICT use, and what they perceive as a good possibility for language improvement, there are differences between male and female students. Most students would not opt for a replacement of a traditional face-to-face contact with ICT. However, since young adults increasingly use ICT for non-educational purposes, it would be irresponsible not to take advantage of that and encourage and teach students to become ICT-oriented when it comes to education.
\end{abstract}

Key words:

ICT, FLL, personality type, traditional methods, gender.

\section{INTRODUCTION}

With the rapid technological advancement and increasingly growing amount of knowledge, the importance of ICT in the learning process is no longer questionable. Not only is its implementation in classroom recommendable, but it seems to be the only way to respond to the ever growing demands on knowledge acquisition. In other words, since traditional learning methods seem to be failing to meet the needs of a modern society, learning environments should rely on more contemporary methods, thus offering a variety of learning activities based on efficient knowledge acquisition strategies. The benefits and potential of ICT are especially prominent in FLL (Foreign Language Learning) and FLT (Foreign Language Teaching), which, being both skill-based and knowledge-based, differ from most other subjects (Fitzpatrick and Davies, 2003). With learning becoming more autonomous, a teacher's responsibility is to grasp individual behaviour and find ways to cater for each individual's needs, interests and learning styles, providing personalised learning environments. However,
Correspondence:

Marija Stanković

e-mail:

mstankovic@singidunum.ac.rs 
a question frequently posed is: can ICT equally support and nourish all four language skills, irrespective of an individual's personal traits and preferences? This paper attempts to examine whether students' knowledge of the English language has been influenced and navigated by the teaching methods used in primary and secondary education and whether such methods were or were not in accordance with an individual's personality type.

\section{Overview of ICT use in education}

In order to gain a better understanding of ICT in teaching/learning processes, its origin, the entire process of implementation from a modest towards a widespread use, its benefits and limitations, as well as its future potential and changes it brings and demands from both teachers and learners, we should begin with a brief overview of the topic and the accompanying concepts in the relevant literature.

Although the use of computers in FLT and FLL began in 1960s, it was only in the mid-1980s that computers became all pervasive and thus easily accessible (Fitzpatrick and Davies, 2003). Nowadays, ICT permeates all spheres of a globalised society, redefining the ways of conducting business and commerce and with an emerging impact on education and training. There are three stages of the so called CALL (Computer Assisted Language Learning), each of them corresponding to technological developments and pedagogical advancements, as well. When behaviouristic approaches to FLT began to be frowned upon, there appeared communicative approaches, only to be soon replaced by constructivist/integrative approaches (Fitzpatrick, 2003). Each of these brought about important changes in the roles of not only the teacher and the learner, but the computer, as well. Firstly, the Internet represents a vast resource of authentic linguistic materials, which enables teachers to step out of the classroom boundaries and, improving their own knowledge, learn to tailor materials to meet the needs of any learner, regardless of their age, level of knowledge, or other. Therefore, implementing ICT in learning processes, teachers abandon their traditional roles and become guides, mentors, facilitators, mediators, researchers, conscientious designers of learning scenarios, collaborators, orchestrators, evaluators and self-evaluators (Fitzpatrick, 2003). Instead of pouring knowledge into the heads of curious and information-hungry students, they are to facilitate the learning process, to guide and enable students to interpret the information they are given and relate it to their prior knowledge and experience. Secondly, the role of the learner has undergone some crucial changes, most important of which is that the learner is no longer an object, but rather a subject, not only with their own needs, interests and cognitive abilities, but also with responsibility for their learning. Like teachers, they also have access to online materials, and instead of being passive recipients of a language, they actively and independently participate in exploring, learning and creating a language, sharing it with their peer learners via ICT. Finally, the role of the computer has changed: originally a tutor, then a tool, now a stimulus in language learning, a data source, a communication facilitator, a tester and, in a way, a teacher (Padurean and Margan, 2009).

\section{Overview of personality types}

Pedagogy and methodology have always relied on psychology, which, on the one hand, has been trying to grasp the general principles underlying the human mind and, on the other, to fathom the uniqueness of the individual mind. Individual differences become especially prominent the moment we claim that the role of the teacher has evolved to that of a tailor of the available authentic material.

Learners differ from each other. Research has shown that individual traits may be the most consistent predictors of L2 learning success, which, unlike L1 acquisition, can range from zero to native-like proficiency (Miyake \& Friedman, 1998). Therefore, language aptitude and motivation are not enough to ensure that the learning process goes smoothly. Due to individual differences, which come in terms of personality, learning styles, anxiety, self-esteem, creativity, willingness to comunicate and other (Dörnyei, 2005), individualised learning techniques are required. According to Carl Gustav Jung, the father of analytical psychology, there are three bi-polar concepts: extraversion-introversion, sensing-intuiting, and thinking-feeling, with each person having a preference for one of the two cognitive functions. A fourth dimension was added by Myers-Briggs in 1970s: judging-perceiving. Nowadays, a very popular model for determining individual differences is the so-called Five Factor Model (FFM), or the Big Five personality traits, which focusses on five dimensions: openness to experience, conscientiousness, extraversion, agreeableness and neuroticism (Dörnyei, 2005). Even though there are some doubts as to whether and to what extent individual differences have an impact on learning, extensive research has shown that at least two of them - openess to experience and conscientiousness - do have, indeed. 


\section{METHOD}

\section{Participants}

The research was done at Singidunum University, Centre Niš, with the first-year students. Immediately upon the admission, all students were required to do an online placement test due to the fact that they came from different towns and different schools and, as a result, were on different level of English proficiency. Based on the results, the students were divided into two groups, a group A consisting of those whose results showed they were either on B1 or B2 level, and group B, who were on A1 or A2 level. Fifty students were recruited for the research, 25 students from group A, and 25 from group B, 25 male and 25 female. All students were 19-22 years old.

\section{Procedure and instruments}

Firstly, the participants were asked to complete the questionnaire created for the purposes of this research, and afterwards to complete a free online personality type test, with previously given oral instructions. Furthermore, the students' scores on the initial online placement test were taken into consideration.

The questionnaire was comprised of ten questions, which can be grouped into three categories. The first category focuses on the participant's exposure to English: how many years the participant has been studying English, whether they have learned it mainly at school, from private teachers, film, music, or video games, and what materials they have been exposed to in their English classes (ranging from a textbook only, to a combination of a textbook, CDs, other audio, video and the Internet material). The second category refers to how often and what for the participant uses a computer and a mobile phone. The third set of questions was aimed to elicit the participant's opinion on whether ICT has improved or can improve their knowledge of English, whether they feel more comfortable learning English online or in a traditional classroom setting, what can improve their knowledge (studying within a small group of students and with a teacher, studying regularly at home, the use of ICT and the Internet, spending some time in an English speaking country, or a combination of at least two previously mentioned methods.

An online free personality test ${ }^{1}$ was used in the experiment. The test consists of 60 questions to which the participant should provide an answer on a seven-step

1 https://www.16personalities.com/free-personality-test scale, from totally agree to strongly disagree, trying to avoid the neutral (middle-step) answer. The test takes 10-15 minutes to complete. The 16 personality test used in this research, is based on the three models - Jung's, Myers-Briggs' and the Five Factor Model, and analyses individual traits in terms of five personality aspects, which, when combined, result in a certain personality type. Those five aspects are: Mind (introverted-extroverted), Energy (observant-intuitive), Nature (thinking-feeling), Tactics (judging-prospecting) and Identity (assertive-turbulent). There are sixteen possible combinations, or personality types. However, since the number of the participants is relatively small, we decided to analyse the results not in terms of every single type, but in terms of four main categories: Analysts, Diplomats, Sentinels, and Explorers. The role layer determines one's goals, interests and preferred activities.

\section{RESULTS}

The data obtained via personality type testing was emailed and later analysed using SPSS software, together with the data obtained via the questionnaire and the placement test scores. The values were presented as mean values. $\mathrm{P}$ values of less than 0.05 were considered significant.

The results obtained can be analysed from three aspects. One part of the questionnaire focused on the participants' exposure to English: how long they have been studying it, whether they have learned it mainly at school, from private teachers, or films, music and video games, and what materials they have been exposed to in their English classes. The results showed a correlation between a personality type and learning from the school teacher $\left(x^{2}=9.36, p<0.05\right)$, where Explorers are most prominent $(M R=30.50)$, then Analysts $(M R=28.50)$, and Diplomats and Sentinels, respectively $(M R=19.30, M R=18.97)$. Also the statistical significance was reached in terms of a personality type and learning from textbooks, with Explorers, Diplomats and Sentinels having the same preference $(M R=22.50)$, and Analysts the smallest one $(M R=16.50)$, where $\left(x^{2}=28.82, p<0.01\right)$. Furthermore, the analysis of the scores on the online placement test has also shown that there is some correlation between the scores and a personality type $\left(x^{2}=15.54, p<0.49\right)$ : Architects/Analysts $(M R=33.38)$, Entertainers/Explorers $(M R=25.50)$, Campaigner/Diplomats $(M R=22.20)$, Protagonists/Diplomats $(M R=21.14)$, Entrepreneur/ Explorers $(M R=20.50)$. 
Secondly, the analysis confirmed that Jung's first variable, Extroverts-Introverts, bears considerable significance. As expected, Introverts are more likely to use the Internet for: searching information $(t=2.35, p<0.05)$, communicating with teachers $(t=2.99, p<0.01)$, studying $(t=2.67, p<0.05)$, and playing video games $(t=1.29, p<$ $0.01)$. On the other hand, Extroverts are more likely to use the Internet for watching films $(t=-0.90, p<0.05)$, and listening to music $(t=1.29, p<0.05)$. Moreover, Extroverts feel more comfortable studying traditionally, from textbooks $(t=2.91, p<0.05)$ and combining textbooks and CDs $(t=1.98, p<0.01)$.

Thirdly, a statistical significance is also evident from the perspective of gender. It is females, slightly more often than males, who use the Internet (4.84 vs. 4.65), look for online information (1.04 vs. 1.00), spend more time on social networks (1.12 vs. 1.03), play video games and learn English by playing video games (1.64 vs. 1.19 and 1.84 vs. 1.38), think that their English would improve by spending some time in an English-speaking country (1.40 vs. 1.15). However, it is males, rather than females, who communicate with teachers via email more often $(1.23 \mathrm{vs}$. 1.08), learned English from school teachers and teaching material such as textbooks, CDs and videos (1.30 vs. 1.16 and $1.88 v s .1 .76)$, and think that their English would get better if they study regularly at home (1.84 vs. 1.60).

\section{DISCUSSION}

From the results obtained in the research, we wanted to see whether using ICT in FLT/FLL has had any impact on the students' proficiency and whether and to what extent one's personality traits are responsible for that impact. We opted for the first-year students, who are on different level of English proficiency, which was confirmed by the online placement test they did immediately upon the admission. Their background data concerning their L2 learning experience was collected via the questionnaire, along with the data referring to their use of ICT and their views on the best ways and means for possible improvements. These two sets of data were compared mutually, as well as with the personality type test results of each student. The objective was to see what correlation, if any, there is between the personality type, the teaching methods, more precisely the use of ICT and the current knowledge of the English language.

When communicative approach was replaced by constructivist approach in the late 1980s, both on theoretical and pedagogical level, there also appeared a need for a more systematic use of ICT in the teaching/learning process. What began to be emphasised was the socio element of learning and thus, until that moment, a pure cognitive view turned into a socio-cognitive view (Fitzpatrick, 2003). The objetive was to create authentic social contexts which would enable the learner to use a language rather than studying about it, an environment which would be fertile for each of the four language skills and which would simultaneously promote, integrate and take advantage of the rapidly growing technology.

What was extremely important was the assumption that each learner is an individual with their own features and preferences, while simultaneously, on the other hand, it was claimed that good language learners share a common set of most prominent personality features, which proved to be consistent in various studies. According to a questionnaire survey by Lalonde, Lee, and Gardner (1987), success in language learning is guaranteed if the learner is meticulous, persevering, sociable, inquisitive, independent, organised, active, involved, flexible, assertive and imaginative. When the door to psychological research was widely opened, it was confirmed that individual traits may be quite reliable predictors of L2 learning success. Among many, the two traits pointed out by most renowned psychologists were conscientiousness and extroversion. Whereas conscientiousness has shown consistent results, extroversion has not always produced positive results in school learning process, which is accounted for by introverts' tendency and ability to consolidate learning, by not being so distractible and by having better studying habits. On the other hand, in formal situations and pressurised environments, extroverts feel more comfortable, they do not feel they are under pressure and they speak more fluently and accurately. Therefore, when it comes to second language learning, it does not necessarily mean that being introverted will inhibit the learning process, or that being extroverted will enhance it. Both extroversion and introversion can be positive, depending on the context.

This was confirmed by our results as well. Those students whose mind was assessed as introverted on the online personality test said that they used the Internet for communication with teachers, searching information, studying and playing video games, whereas those whose Mind was assessed as extroverted said that they used the Internet for watching films and listening to music, and that they preferred studying from textbooks and CDs. However, the Explorers, who said that they had learned language mostly from school teachers and from textbooks, did not have the best scores on the placement test. 
Finally, some of the results obtained in terms of gender are somewhat surprising: the female students use the Internet more often, they play video games, and believe their English would improve if they were to spend some time in a foreign country, unlike the male students, who had learned mostly from school teachers and textbooks, CDs and videos, and who said that they would rather communicate with their teachers via email.

Nowadays, when traditional methods do not seem to be enough to respond to the growing demands for knowledge the use of ICT in education is more than advisable. Learning is becoming more and more autonomous and the teacher is expected to fathom each learner as an individual and to provide personalised learning environment, responding, on the one hand, to individuals needs and learning styles and, on the other hand, enabling students to respond to the needs of society. The teacher has the responsibility to take advantage of the all-pervasing ICT and encourage and teach students to become conscious of the benefits and necessities of ICT in a life-long educational process.

\section{CONCLUSION}

The aim of this paper was to examine the effect of ICT use in the process of foreign language teaching and foreign language learning in relation to personal traits. In order to do so, firstly, we had to establish the current level of students' English proficiency, which had been done by students doing an online placement test; secondly, we had to obtain the information about whether students had been using ICT in the process of learning during their primary and secondary education, i.e. how often and what for they used the computer, which was done via the specially created questionnaire; thirdly, it was necessary to find out each student's personality type by asking them to do an online personality type test. This small-scale research included 50 first-year students at Singidunum University, whose English knowledge ranges from $\mathrm{A} 1$ to $\mathrm{B} 2$. The results obtained in the study show a certain correlation between being extroverted or introverted and the teaching methods used in FLT, thus confirming numerous previous studies which claim that whether or not one will learn successfully a second language indeed depends on what type of person he or she is and, consequently, whether or not the teaching material and methods are designed to satisfy one's needs, interests and learning habits. Given that this was a smalescale research, further research is needed to definitely confirm this and, possibly, establish additional correla- tions between the degree of ICT exposure, personality type and the proficiency.

ICT has already modified the culture of learning and yet it is going to bring about even more changes. Nowadays, the positive aspects and the necessity of implementing ICT in language teaching and learning processes are unquestionable. Just as the computer has evolved to revolutionise our social life, so has it altered both the teacher and the learner. Once the objective of language teachers was to ensure that students spend endless hours trying to memorise grammar rules and vocabulary. This was then replaced by the one which insisted on encouraging and motivating learners to develop communication skills. A $21^{\text {st }}$ century language teaching goal is to enhance the human and social development of students and community (Warschauer, 2002), not only by trying to simulate the atmosphere of an authentic environment, but rather by finding one and introducing students to it. Mastering language skills should not be separate from mastering technology, or other areas of interest. Encouraged to satisfy their own needs and interests, whether in self-directed and independent activities, or in interactive, cooperative work, learners take on teaching roles and, consequently, the responsibility. Nonetheless, with the increase of responsibility on the part of the learner, the teacher's responsibility does not decrease; quite the contrary, having to assume multiple roles and functions instead of only one, the teacher has gradually turned into a learner himself.

\section{REFERENCES}

Dörnyei, Z. (2005). The Psychology of the Language Learner: Individual Differences in Second Language Acquisition. University of Nottingham, Lawrence Erlbaum Associates, Publishers Mahwah, New Jersey, London. Retrieved January 17, from https:// cstn.files.wordpress.com/2009/11/the-psychologyof-the-language-learner-3haxap.pdf

Fitzpatrick, A. (2003). Information and Commnication Technology in Foreign Language Teaching and Learning - An Overview. In Fitzpatrick, A. (Ed.), Information and Communication Technolgies in the Teaching and Learning of Foreign Languages: Stateof-Art, Needs and Perspectives. Unesco Institute for Information Technologies in Education, Moscow, 2004.

Fitzpatrick, T \& Davies, G. (2003). The Impact of Information and Communications Technologies on the Teaching of Foreign Languages and on the Role of Teachers of Foreign Languages: a report commis- 
sioned by the Directorate General of Education and Culture. Retrieved January 20, from http://www. nefmi.gov.hu/letolt/nemzet/ict_030311.pdf

Lalonde, R. N., Lee, P. A., \& Gardner, R. C. (1987). The common view of the good language learner: An investigation of teachers' beliefs. Canadian Modern Language Review, 44, 16-34.

Miyake, A., \& Friedman, D. (1998). Individual differences in second language proficiency: Working memory as language aptitude. In A. F. Healy \& L. E. Bourne (Eds.), Foreign Language Learning: Psycholinguistic studies on training and retention (pp. 339-364). Mahwah, NJ: Lawrence Erlbaum Associates.
Padurean, A. \& Margan, M. (2009). Teaching Via ICT. Revista de Informatică Socială vol. VII nr. 12 / Decembrie 2009 ISSN 1584-384X. Retrieved February 3 , from http://www.ris.uvt.ro/wp-content/uploads/2010/01/apadurean.pdf

Warschauer, M. (2002). A Developmental Perspective on Technology in Language Education. TESOL Quarterly, 36, 453-475. 